\title{
Impact of Risks and Uncertainties on Supply Chain: A Dairy Industry Perspective
}

\author{
Pramod Kumar Mishra (Corresponding Author) \\ School of Management Studies, University of Hyderabad \\ Central University P.O., Hyderabad, PIN - 500046, India \\ Tel: 91-888-048-5386 E-mail:pkmmba@gmail.com
}

Prof. B. Raja Shekhar

School of Management Studies, University of Hyderabad

Central University P.O., Hyderabad, PIN - 500046, India

Tel: 91-40-6679-5003 E-mail: b_rajashekhar@yahoo.com

Received: May 6, 2011 Accepted: May 24, 2011 doi:10.5296/jmr.v3i2.651

\begin{abstract}
No business organisation is out of purview of risks and uncertainties and hence the dairy industry is no deviation. Dairy industry which plays a crucial role in agro-based economy of a country provides enough scope to the rural and sub-urban people to earn extra money in their leisure time. The industry is extended from a milk producer in the rural area to a consumer in the urban area through some of the core processes like pasteurisation and transportation. The dairy food supply chain which entangles several stakeholders in the system gets disrupted many a times due to various vulnerabilities in the operation. The vulnerabilities in terms of risks and uncertainties get multiplied with the perishability nature of the raw material that is milk which the industry deals in. The study will discuss about the various risks and uncertainties from a dairy industry perspective and their impact at various stages of the supply chain. Mostly survey based research method has been adopted to gather information from various stakeholders in the system along with in-depth personal interviews with the corporate authorities. In the findings section the major risks are discussed along with their impact on the supply chain at various stages. The findings could be further verified in other dairy food supply chains so as to make it wide.
\end{abstract}

Keywords: Supply chain, Risk and uncertainties, Impact 


\section{Introduction}

Starting from the ancient stone era to the till dated information era human has had tried to make his living easy and subtle by removing uncertainties and minimising risks. Today's business organizations are also no deviation in this regard. Keeping view to the enormous competition in the market place and the excessive political and bureaucratic interventions the organisations are striving hard to overcome uncertainties and risks which are leading to shorter product life cycles and a great deal of customer distraction towards the product or service. That's the reason why the organisations are formulating and implementing various strategies to overcome these barriers.

Supply chain in any industry is entangled with many stakeholders and so is supply chain risk. Earlier the risks and uncertainties in the supply chain were dealt with as a company specific task (Juttner, 2005). It is today realized that since the supply chain is a complex bonding of several stakeholders, distortion at one of the components distorts the entire chain in varying degrees.

Risk management is a proactive approach rather than reactive approach (Gray \& Larson, 2008). The risk management process starts with identification of the risks and ends with the risk mitigation through the risk response development. Risk mitigation, avoidance, transferring, sharing and retaining are the various responses to deal with the risks in the organisation.

Of late, supply chain risk management has gained attention throughout the world. Identifying potential supply chain risks and unearthing a suitable strategy to mitigate these risks have been found to be the key success factor irrespective of the kind of organisation. Though not much of work is done in this context still some of the empirical works published by various theoreticians and practitioners will give direction for others to opt for the critical issues and a prospective solution thereto in the supply chain. So, there is a need for research to fortify the concept (Thun \& Hoenig, 2009; Juha \& Pentti, 2008). The main objectives of this paper have been to detect the potential risks in varying degrees for the dairy-food supply chain and investigating their impact at various stages of it.

\section{Review of literature}

Overview of some of the literature based on the supply chain risk has been cited hereunder to strengthen the study. The following discussion will focus on the issue and will try to avoid exaggerations.

Definitions of risk and risk management are multifarious, and many have emerged over time (Zsidisin, 2003). Of particular interest in the present study is "supply (chain) risk", which refers to risk associated with inbound supply and the subsequent impact on customers (Zsidisin, 2003). For example, the British Standards Institute (BS 4778, 1991) defined risk as a "combination of probability or frequency of occurrence of a defined hazard and magnitude of the occurrence."

The risks involved in the supply could impede the flow of the supply chain. Zsidisin in his 
study in the year 2003 has suggested a grounded definition of risk after having a case study research wherein he has taken five electronics and two aerospace firms along with the existing literature before him. According to him:

Supply risk is defined as the probability of an incident associated with inbound supply from individual supplier failures or the supply market occurring, in which its outcomes result in the inability of the purchasing firm to meet customer demand or cause threats to customer life and safety. (p. 222)

Risk and uncertainty, though used interchangeably in various studies, are not one and the same. Wherever in case of risk the probability is known, it is not known for the uncertainty. But both incur losses to the supply chain (Siegel, 2005). In this study the risk and uncertainty have been used to be a phrase rather than any other distinctions between them. The rationale behind this is the discussed risks are with their known probabilities and hence the difficulties in anticipating them in the supply chain are also low.

Supply chain risk management is at infancy stage and getting extremely popular research area today. Vanany, Zailani and Pujawan (2009) reviewed 82 relevant articles pertaining to supply chain risk management from several established journals and data bases from the year 2000 to 2007. They have segregated these papers on the basis of type of risk, unit of analysis, industry sectors and risk management processes/strategies. Understanding, identifying and assessing the risks based on probability of occurrence and severity of impact is a starting point for companies to develop effective risk management strategies, they add.

Schoenherr, Tummala and Harrison, in their 2008 study, have highlighted the risk issues pertaining to the sourcing or purchasing decisions in the supply chain. This decision in the production process might give rise to poor quality, higher transportation costs, lower reliability, supply disruptions, logistical failures, natural disasters and increased communication difficulties etc, they have cited. In order to find the best solution for this they have undergone through the Action Research method with the help of Analytic Hierarchy Process (AHP). They have identified 17 risk factors and then used AHP to evaluate the importance of each risk factor, and to determine the best alternative. According to them product cost and quality are highest vulnerable areas associated with the off-shoring decisions, putting natural disasters and engineering and innovation as the least concerned areas in it.

Thun and Hoenig (2009) have conducted a survey of 67 manufacturing plants in German automotive industry for investigating the vulnerabilities of supply chains. They have found that supply chain risks are predominantly vulnerable wherein globalisation, product variant, supplier reduction and the outsourcing are some of the key drivers which disrupt the chain. According to them the internal supply chain risks are more likely to occur and affect the supply chain performance more adversely which has taken to be one the hypotheses of our study. The study says companies with higher degree of supply chain risk management perform better than others who perform at a lower level of it. Furthermore, the results show that the group using reactive supply chain risk management has higher average value in terms of disruptions resilience or the reduction of the bullwhip effect, whereas the group pursuing preventive supply chain risk management has better values concerning flexibility or safety 
stocks.

There seems to have a crucial role of the suppliers in the whole supply chain. The suppliers' risk coping efficiency is one of the major antecedents for it. The problems pertaining to financial instability, capacity constraints, quality related risks and the technological changes are the major variables found disrupting the suppliers' stand in the supply chain (Zsidisin \& Ritchie, 2008). He has further opined that the supply risk depends on the risk sources and outcomes whereas understanding the risk sources differs from industry to industry. Supply chain risks are increasingly rampant in the globalised era. All decision makers of the supply chain have to come across this deadlock. This has been reiterated by Akcaoz, Kizilay and Ozcatalbas (2009). They have conducted a survey of 75 dairy farmers in the Antalya province of Turkey in order to know the risk management strategies in the farms during the year 2007. In all the farms irrespective of their size - milk price variations, lack of hygienic conditions and the meat price variability have been found to be three major risk sources keeping aside the marketing problems. They have also identified that, keeping the debt low, producing at the lowest cost possible and good liquidity conditions are the key risk management strategies followed there.

Procurement is one of the key activities of the supply chain management. It has been seen that the organisation's 60 percent of the sales income is invested for the procurement of material ((Tiersten, 1989). Procurement related risks are oftentimes perceived differently by the industry people, how they are tolerated and managed. Whereas the high-tech organisations follow the informal and decentralised process in the risk management, there the traditional manufacturing ones are leaned towards the centralised and formal process (Juha and Pentti, 2008). The qualitative study by Juha and Pentti on eight traditional manufacturing companies and seven high-tech companies in Finland reveals the results. They have suggested that "perceived risk of a buying task can be most efficiently managed by changing dynamically buying centre structure to different buying situations and during the buying process". Companies should utilize their internal networks more efficiently as well to manage the purchase-related risks, they highlight in their study.

Managing supply chain risks has become one of the major concerns in the value chain. Though the severity of the risks get realised in varying degrees across the supply chains, organisations perceive the risks in different ways. Some are risk takers whereas some are risk avoiders and want to be at the safe side of the risks. No matter what a company's attitude is in risk management, there is a little bit of impact realised throughout the chain. To know about how companies react to the risks, the Economist Intelligence Unit (2009) surveyed 500 executives from various companies across Asia-Pacific, North America and Europe. The result says that, 62 percent of the respondents cite demand unpredictability as one of the major disrupting force in the supply chain. More than one-half of all respondents have been hit by the rising input costs and volatility in energy prices and over one-third has been affected by the insolvency of partners or suppliers. According to this, one-half of the respondents are found to be opined for improving the collaborations with the partners or suppliers as the major weapon to combat supply chain risks. 
Ramaswami, Ravi and Chopra (2004) have defined the agricultural related risks what an Indian farmer usually face these days. Some of the major threats the Indian farmers are facing today are declining size of the land holding, degradation of soil and water resources, inadequate institutional credit support and lack of opportunities for non-farm employment etc., they have cited in their book on State of the Indian farmer: Risk management (Vol. 22). According to them there are basically two types of risk at the farm level. They are agricultural risk and non-agricultural risk. Production risk (weather, pest and diseases), price risk (lack of demand) and input risk (shortage of inputs or when their prices vary) are the risks come under the agricultural risks. There are certain risks which are common to all are called as systematic (covariate) risks and risks specifically related to a particular farmer are termed as idiosyncratic risks. Risk management and mitigation can be done at the farmer level or at the community level as a whole. This can be done either with the help of self-insurances for the crops or risk pooling and mutual insurance at the community level - they have added to their work as a method of risk management strategy.

The asymmetric information between the suppliers and the manufacturer could lead to supply chain disruption and finally lead to market failure. The study by Gorton et al. (2006) in Moldova has tried to look into the issue. The authors with the help of a dairy case have suggested that rebuilding relationships, contracting and strengthening of the village collection centres could ease the problems. Though he has not specifically cited any risks in the dairy food supply chain still some of the problem areas with the cooperative societies are considered in this case as risks.

Akcaoz et al. (2009) have conducted a survey of dairy farmers in the Antalya province of Turkey in order to know the risk management strategies in the farms. In all the farms irrespective of their size - milk price variations, lack of hygienic conditions and the meat price variability have been found to be three major risk sources keeping aside the marketing problems. They have also identified that keeping the debt low, producing at the lowest cost possible and good liquidity conditions are the key risk management strategies followed there.

Ali and Kapoor (2008) have discussed about various types of risks for the fruits and vegetables. Investment, socio-economic, environmental, production and market risks are the major perceived risks in the production of fruits and vegetables. Price and production risks are the most vital risks in this case - they have mentioned. Better risk management in this can be done through the improved information technology, development of financial markets and promotion of market based price ensuring marginal farmers to get benefit out of it.

\subsection{Research gaps and look out of the study}

Supply chain risk is a new concept these days and hence will take some time to get fortified. After reviewing requisite literature it is realized that supply chain risks issues in the dairy industry could be discussed to make it little wide and conceptual. The risks and uncertainties in the dairy industry have been discussed hence forth with their implications on the supply chain itself. 


\section{Scale for measuring the impact of supply chain risks}

As discussed earlier in the literature the risk is an even influencing the supply chain negatively with a known frequency or likelihood the following discussion is describing it in a mathematical way to find the impact of the same (Mulacahy, 2003).

Risk $=f($ Likelihood, Severity):

If, Likelihood $=$ P, Severity $=$ S, Impact $=$ I;

Where $\mathrm{I}=\mathrm{P} * \mathrm{~S}$;

P: 1=very low (0.0-0.2), 2=low (0.2-0.4), 3=medium (0.4-0.6), 4=high $(0.6-0.8), 5=$ very high $(0.8-1.0)$;

S: $1=$ insignificant, $2=$ minor, $3=$ =neither serious nor minor, $4=$ =serious, $5=$ catastrophic; and

I: $1=$ very low (1-5), 2=low (5-10), 3=medium (10-15), 4=high (15-20), 5=very high (20-25).

The probabilities or likelihoods have been considered by consulting the dairy experts and researchers. Other scales are according to the Likert five-point scale which is well established in the field of empirical research and requires no further discussion.

\section{Materials and methods}

\subsection{Target population}

The dairy industry in India is mainly constituted of 15 major state milk federations having more than 177 milk unions, 110,000 dairy cooperative societies involving 12 million milk producers. Britannia, Nestle, Mother Dairy and some regional private companies' existence is further cherished the industry. State milk federations are the major players in their respective states. It may be noted here that Gujarat Cooperative Milk Marketing Federation (GCMMF) is marketing different dairy products under its well known brand 'AMUL' throughout the country and abroad. For the recent study similar to GCMMF - Orissa State Cooperative Milk Producers' Federation (OMFED) has been considered. The federation involving seven major stakeholders in its day to day operations has been depicted in the following flow chart:

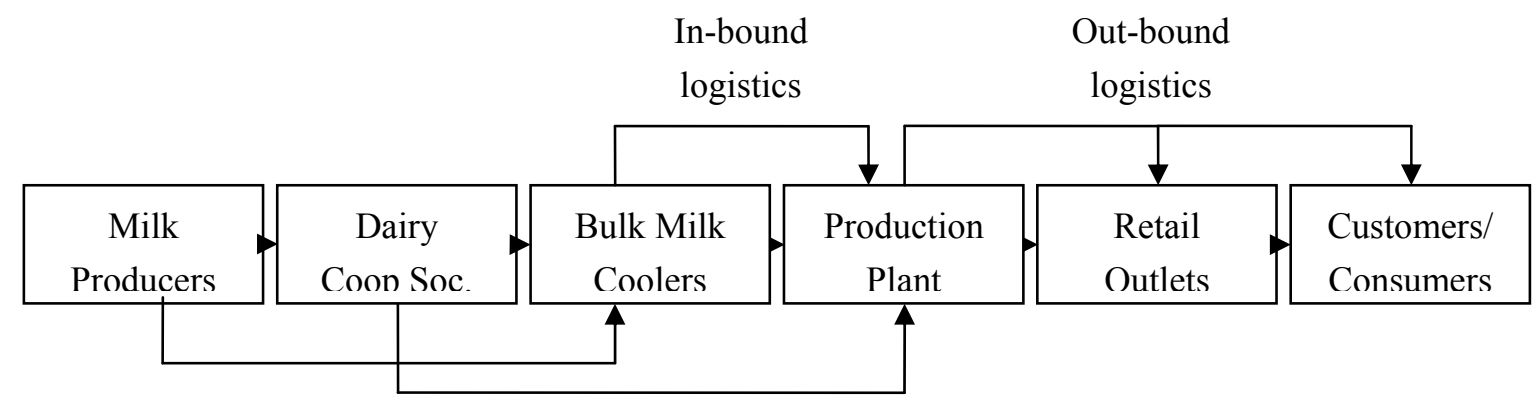

Figure 1. Dairy food supply chain

The study covers all the stakeholders in the system so as to identify risk and uncertainties for the entire supply chain and their possible impact on it. 


\subsection{Sampling frame}

It may be noted here that the sample has been drawn on this premise from the target population cited above. The proposed sample is based upon 95 percent confidence level and 5 percent error suggested by Krejcie and Morgan (1970) for any empirical research. The non-response rates mentioned in the table 1 is found to be insignificant by Wilcoxon and Sign tests at 5 percent level of significance or 95 level of confidence. The reliability (Cronbach $\alpha$ ) of more than or equal to 0.7 of an instrument is satisfactory as opined by many researchers (Nunnally, 1978; Malhotra et al., 1998; Hair et al., 1998).

Table 1. Sample distribution

\begin{tabular}{|c|c|c|c|c|c|c|c|c|}
\hline $\begin{array}{c}\text { Sample } \\
\text { description }\end{array}$ & $\begin{array}{c}\text { Milk } \\
\text { Producers } \\
\text { (MP) }\end{array}$ & $\begin{array}{c}\text { Dairy } \\
\text { Coop. } \\
\text { Societies } \\
\text { (DCS) }\end{array}$ & $\begin{array}{c}\text { Bulk } \\
\text { Milk } \\
\text { Cooler } \\
(\mathrm{BMC})\end{array}$ & $\begin{array}{c}\text { Production } \\
\text { Plant } \\
\text { Officials } \\
\text { (PPO) }\end{array}$ & $\begin{array}{c}\text { Transport } \\
\text { Officials } \\
\text { (TO) }\end{array}$ & $\begin{array}{c}\text { Retail } \\
\text { Outlets } \\
\text { (RO) }\end{array}$ & $\begin{array}{c}\text { Customers } \\
\text { (CUS) }\end{array}$ & Total \\
\hline $\begin{array}{c}\text { Proposed sample } \\
\text { (nos) }\end{array}$ & 382 & 191 & 36 & 20 & 20 & 172 & 382 & 1203 \\
\hline $\begin{array}{l}\text { Actual sample } \\
\text { (nos) }\end{array}$ & 348 & 168 & 33 & 20 & 20 & 150 & 324 & 1063 \\
\hline $\begin{array}{c}\text { Non-response } \\
\text { rate }(\%)\end{array}$ & 8.9 & 12.0 & 0.0 & 0.0 & 0.0 & 12.8 & 15.2 & 11.64 \\
\hline $\begin{array}{l}\text { Instrument } \\
\text { reliability }\end{array}$ & 0.70 & 0.76 & 0.80 & - & - & 0.70 & 0.79 & - \\
\hline
\end{tabular}

Altogether there are 1063 sample respondents have been considered including the plant manager of the dairy and the managers of two transportation companies. The transportation is basically an outsourced activity followed in the dairy federation being discussed here. From the procurement chain - BMCs, DCSs and the MPs are approximately in the ratio 1:5:12. Similarly, from the distribution chain ROs and the CUs are approximately in the ratio 1:2 excluding the production plant and transportation companies. As far as the geographical locations are concerned all the operational areas of the dairy have been fully exploited to study the potential risks for the entire chain.

\subsection{Data collection and analysis}

This survey conducted during July 2009 to April 2010 has been further validated by pilot testing and action research technique after it is found inefficiency of the respondents to answer the certain queries in the questionnaire. Separate questionnaire for each component has been adopted in the process. Altogether there are seven questionnaires have seven referred to in the survey process. The questionnaires are based upon the various risk areas meant for the dairy food supply chain wherein the opinions of the respondents have been 
gathered to identify the potential risks for the industry as a whole. Complementary questions are also asked over phone and email so as to fructify the data collected. The basic intention behind this has been to get acquainted with the intricacies of the dairy food supply chain where the data collected is not enough to analyse certain aspects of it. The data collected are analysed with the help of SPSS 17 in order to draw inferences out of it.

\subsubsection{Techniques used for analysis}

As cited above in the scale section the impact of all the risks have been calculated individually and finally the overall impact has been calculated on the basis of weighted average method. Multiple regression technique has been used to represent the individual risks corresponding to the overall risk impact. In this case the coefficient of determination, variability and Durbin-Watson are calculated to avoid sample bias. The details will follow in the result and discussion section. Multiple regressions are a well established fact used in various literatures and no need of further discussion.

\subsection{Scope of the study}

It is estimated that only about 5 percent of the milk market is handled by the organized sector in Orissa (IFCN, 2008; FAO, 2008) and the rest 95 percent of the market is unorganized. OMFED is a major contributor in the organized milk sector in the state covering all the 30 districts. Currently it is functioning with around 65 percent of the market share. It has a vast milk producer network organized into the dairy cooperative societies. The operation of this public sector company is replicating the "Anand Pattern" of dairy industry in Gujarat. The pattern of dairying is similar to the figure 1 mentioned above which has got three levels of milk procurement and sales that is village, district and state. At village level milk producers are united to form a cooperative society and the cooperatives in return form a union at the district level. Finally the unions of the districts form a federation at the state level which takes care of all the stakeholders by getting funding from World Bank, FAO, planning commission of the central government, state government and other social non-profit organizations etc. the federation is operates like a public sector organization with due representations from the district level unions by registering itself with the Registrar of Cooperative Society of the central government.

\section{Results and discussion}

Initially there are 36 risk areas detected throughout the supply chain but due to high coefficient of variations in certain cases and not gathering of much opinion against those rule them out from the study after a preliminary analysis. The number of risk areas considered at each level with their coefficient of determination (R), representation of sample to the population (adjusted R square) and auto-correlation values (Durbin-Watson) have been depicted in the table below: 


\section{Mll Macrothink}

Table 2. Fitting of the model

\begin{tabular}{|c|c|c|c|c|c|c|}
\hline $\begin{array}{c}\text { Components } \\
\text { of figure } 1\end{array}$ & $\begin{array}{c}\text { No of risks } \\
\text { considered }\end{array}$ & $\mathrm{R}^{*}$ & $\mathrm{R}$ square & $\begin{array}{c}\text { Adjusted } \\
\text { R square }\end{array}$ & $\begin{array}{c}\text { Std. error } \\
\text { of estimate }\end{array}$ & Durbin-Watson \\
\hline MP & 5 & 0.75 & 0.57 & 0.56 & 0.25 & 1.96 \\
\hline DCS & 5 & 0.72 & 0.51 & 0.50 & 0.29 & 2.06 \\
\hline BMC & 5 & 0.78 & 0.61 & 0.53 & 0.26 & 1.99 \\
\hline PP & 6 & 0.86 & 0.74 & 0.63 & 0.22 & 1.98 \\
\hline TA & 4 & 0.71 & 0.51 & 0.50 & 0.28 & 2.09 \\
\hline RO & 2 & 0.72 & 0.52 & 0.51 & 0.40 & 2.00 \\
\hline CUS & 2 & 0.76 & 0.57 & 0.57 & 0.32 & 2.03 \\
\hline
\end{tabular}

In total 14 risk areas are carried forward from the preliminary analysis and the results are mentioned in the table above. It can be understood that some of the risks are repeating at some other stages where some are solely meant for a specific stakeholder. The maximum number of risks is associated with the production plant whereas the least are experienced at the customers' level. At each level the variability is more than 55 percent which indicates the fit of the model to the population of the state as well to the country. All the Durbin-Watson values are close to 2.0 and hence the possibilities of auto-correlations are overruled. All the risks and uncertainties discussed are found to be significant at 5 percent level of significance and hence finally categories as per their consistency of impact on the supply chain. The high fluctuations in the impact have been treated as low category risks and are mentioned in the lower part of the table below.

\subsection{Detection of risks and uncertainties}

There are 14 risks detected across the supply chain as mentioned in the previous table with their varying impact being categorised as high, medium and low. These risks directly or indirectly affect the efficiency and effectiveness of the supply chain with around 55 percent of variability. Since the supply chain is an integrated process; the occurrence of problem at any stage of it puts the whole supply chain at stake. Hence though some of the risks are experienced at a particular level still the indirect impact of the same on other levels can't be overruled. 
Table 3. Categorising risks

\begin{tabular}{|c|c|c|c|c|c|c|c|}
\hline $\begin{array}{l}\text { S1. } \\
\text { No }\end{array}$ & Risk description & Probability & Severity & Impact & $\begin{array}{l}\text { Standard } \\
\text { deviation }\end{array}$ & $\begin{array}{l}\text { Coefficient } \\
\text { of variation }\end{array}$ & $\begin{array}{c}\text { Risk } \\
\text { Category }\end{array}$ \\
\hline 1 & Low milching cattle & 4.45 & 4.60 & 4.20 & 1.10 & 26.00 & High \\
\hline 2 & $\begin{array}{l}\text { Illiteracy of the milk } \\
\text { producers }\end{array}$ & 4.08 & 4.34 & 3.80 & 0.98 & 26.00 & High \\
\hline 3 & $\begin{array}{l}\text { Non-remunerative } \\
\text { price of milk }\end{array}$ & 4.03 & 4.22 & 3.64 & 1.12 & 31.00 & High \\
\hline 4 & Logistical risks & 3.50 & 4.00 & 3.25 & 1.12 & 34.00 & High \\
\hline 5 & Hazard risks & 3.71 & 4.02 & 3.30 & 1.12 & 34.00 & High \\
\hline 6 & $\begin{array}{l}\text { Demand } \\
\text { unpredictability }\end{array}$ & 3.53 & 3.68 & 2.98 & 1.12 & 38.00 & High \\
\hline 7 & $\begin{array}{l}\text { Lack of product } \\
\text { reliability }\end{array}$ & 3.22 & 3.91 & 2.93 & 1.18 & 40.00 & High \\
\hline 8 & $\begin{array}{l}\text { High cost of fodder } \\
\text { and medicines }\end{array}$ & 3.18 & 3.65 & 2.68 & 1.12 & 42.00 & Medium \\
\hline 9 & $\begin{array}{l}\text { Lack of leadership } \\
\text { skills of secretaries }\end{array}$ & 3.13 & 3.40 & 2.67 & 1.18 & 44.00 & Medium \\
\hline 10 & Delivery risks & 3.69 & 3.15 & 2.73 & 1.28 & 47.00 & Medium \\
\hline 11 & Product shortages & 2.45 & 3.30 & 2.05 & 1.00 & 49.00 & Medium \\
\hline 12 & $\begin{array}{l}\text { Seasonal fluctuations } \\
\text { in production }\end{array}$ & 3.43 & 3.06 & 2.55 & 1.32 & 52.00 & Low \\
\hline 13 & $\begin{array}{l}\text { Process/control/quality } \\
\text { risks }\end{array}$ & 2.29 & 2.54 & 1.75 & 0.93 & 53.00 & Low \\
\hline 14 & $\begin{array}{l}\text { Incompatible price } \\
\text { w.r.t quality }\end{array}$ & 2.30 & 3.45 & 2.10 & 1.25 & 60.00 & Low \\
\hline
\end{tabular}

\subsection{Impact of high risks on supply chain}

These risks directly or indirectly affect the efficiency and effectiveness of the supply chain with around 55 percent of variability. If these risks are addressed with due planning half of 
the supply chain risks can be avoided. The impact of these risks and uncertainties across various levels of the supply chain are being discussed below.

\subsubsection{Low milching cattle}

Rearing of low milching cattle brings down the production and hence increases the cost of production. It has been seen that, the higher is the production; the lower is the cost of production per litre of milk. This is the minimum when somebody is producing up to 60 litres of milk per day (figure 2). But for typical milk producer, who owns one to two cattle (almost 45 percent cases) produces below 10 litres of milk per day and each 5 litre in a shift. This clearly says that average milk from a cattle is around 2 litres per shift (morning/evening) which obviously can't cater to decrease the cost of milk production at one go. It has been seen that at 99 percent level of confidence, cost of production and average daily production of milk are correlated with a coefficient of 0.40 .

This is the direct impact of the low milching cows on the performance of the milk producers. This also holds good for the stakeholders on the downstream. They suffer from the low milk collection and hence lead to the low level of procurement both at the chilling centres and production plant which substantially increase the cost of chilling, transportation and processing.

Lower involvement of the milk producers in the societies brings down collections and lower level of collection due to low production increase the cost of collections and decrease profit substantially thereto. It is found that the correlation between average milk collections and cost of collections is around 0.45 (significant at one percent).

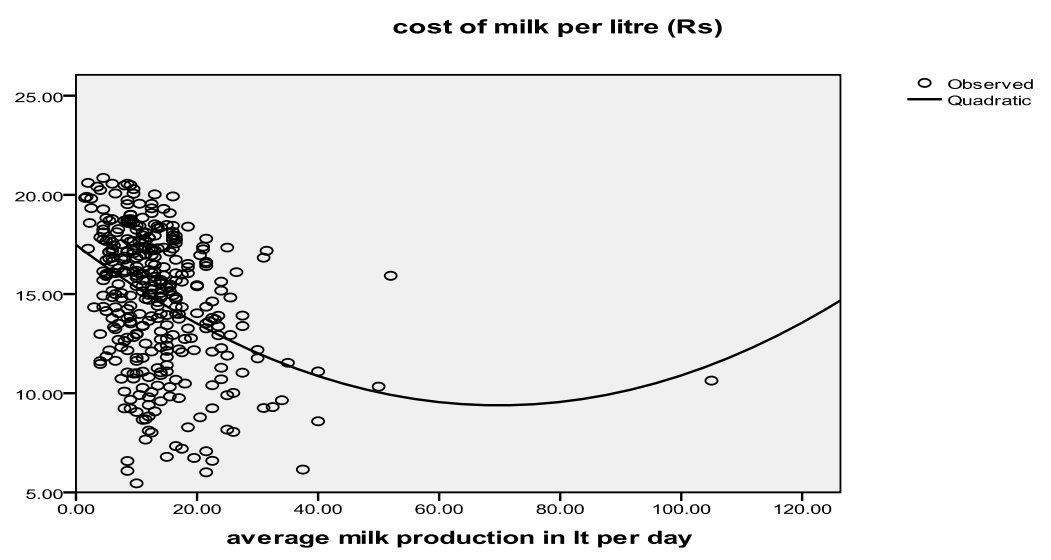

Figure 2. Variation of cost of milk with respect to production

The cost of collection in the flush seasons and lean seasons are respectively Rs.0.33 and Rs.0.16 per litre respectively with a mean of Rs.0.25. The cost of collection is doubled in the lean seasons due to decrease in the collections. Though both net profits and return on investment (ROI) are found to be affected by this; the former is affected substantially by 90 percent (five percent level). These high deteriorations of profit make the societies unstable and sick in the long run to be wiped out finally. 
At BMC level the lower level of milk procurement has a tremendous impact. It substantially decreases capacity utilization of the plant which ultimately increases the cost of chilling and transportation by bringing down the profit. It is found that BMCs' on an average incur Rs.1.98 per litre of milk towards cost of collection, chilling and transportation of which respectively, 19 percent (Rs.0.37) and 25 percent (Rs.0.50) of it is expended towards secretaries' commissions and head loaders' compensations. Respectively 18 percent (Rs.0.36) and 32 percent (Rs.0.64) is expended towards the cost of chilling and transportation. The rest is expended towards housing, maintenance and depreciations of the machineries. Clearly the lower level of collections will bring up all these costs and reduce the monthly profit drastically. Wherever the average profit per litre of milk is calculated to be Rs.0.15 with an average collection of 24,450 litres per month; the deterioration in the collections will severely impact the profit. It may be noted here that most of the BMCs (40 percent) are incurring losses whereas the average ROI is around 4.6 percent.

\subsubsection{Illiteracy of the milk producers}

There is no proper correlation found between the cost of production and the illiteracy of milk producers still, in most of the cases it creates problem in understanding the intricacies of milk production as per the norms and standards fixed by the federation from time to time. This sometimes brings up cost of production and quality deterioration at their level. Lack of understanding of the business facts bring down bargaining power at the DCS level and hence get underpaid for their produce; which ultimately snatches their avocation being suffered for a long time. In this way the risk not only makes the milk producers as sufferers rather it affects the DCSs at same capacities.

\subsubsection{Non-remunerative price of milk}

Non-remunerative price does not affect the cost or quality of milk directly but certainly won't entice the producers from the unorganized sector to join the societies. Moreover the lesser price of milk incurs losses and hence makes them bankrupt over a period of time which compels the milk producers to sell off their milching cattle. It is also seen that average year of experience of a milk producer in dairying is more than seven years while average time he/she has spent in the societies is lesser than half of the former (4 years). It shows the milk producers join societies much later than they start dairy farming and after being there for a specific period of time leave the organization. If they won't do the same - informal milk selling becomes a part of their business in a guised way.

At the society level the non-remunerative price of milk dissuades the producers from joining societies. It is seen that on an average one third of the milk producers from a locality are involved with the society operation. On any given period of time pouring members (active members) are found to be two third of the total members, which could be attributed to the non-remunerative price of milk. This not only brings down the involvement of producers in the system rather substantially affects the collections at their disposal.

\subsubsection{Logistical risks}

The flow of materials from one place to the other inevitably concerns a lot for the production 
plant and for other stakeholders too. The delay in the process deteriorates production and distribution which ultimately lead to customer dissatisfaction. Since the production only deals with the out-bound logistics the delay in it only hampers distribution processes and cause perishability of products on the way to some extent. It is explored that the logistical risks only contribute to more than half of the total risks experienced at the production plant. Indirectly it brings in customer dissatisfaction which may lead to loss of market share.

The distribution of the items is taken care of by the transport agencies who are the third party logistics providers (TPLs). The deviations in making the product available to the retail outlet create discontentment among them and lead to file complaints at the production plant authorities. Since the products are highly perishable and making them reach on time is a key issue. In order to confine to the stipulated timings and promise the logistical flow is made highly agile which sometimes (20 percent cases) faces road casualties leading to loss of property and lives.

\subsubsection{Hazard risks}

The risks like fire, sabotage, accidents or bandhs (stopping of normal life by politicians or due to various agitations/protests) etc. could be attributed to hazard risks. This kind of risks, though applicable to BMCs and the production plant, still found to be a high risk area for the transport agencies too. The transport agencies who work for the out-bound logistics sake, selected through a bidding process. Once the products handed over to these agencies at the plant, the onus of these items are borne by them and any deviation in distribution lead to penalization. So these agencies are highly susceptible to hazard risks which not only result in penalisation rather lead to bring down profit and sometimes loss of lives during transportation.

\subsubsection{Demand unpredictability}

Unpredictability of demand in the market place doesn't allow the retailers to put exact advance in front of the production plant. Though in case of packaged milk sale, the amount of it through home delivery is known, still nothing is known about the counter milk sale. All it depends upon the customers' turn up at the counter to purchase the same - which is absolutely a chance. In this connection the experience of a retailer about the market which he/she deals in - matter a lot. It is seen that the counter sales of packaged milk is more than half of total milk sales and the rest is made through the home delivery process. So the higher amount of milk to be sold at the counter, the greater is the difficulty in predicting the demand. Similar kind of problem is also noticed in case of sale of dairy products.

Since no credit system prevails in the system, the order is made on the basis of advance payment and hence risk aversion in case of putting higher order has been rampant in their case. Since all these orders reflect the production output of the plant it operates in a sub-optimal level in meeting the demand.

\subsubsection{Lack of product reliability}

Variations in quality and taste of the dairy products lead to customer dissatisfaction and are 
apparently seemed to be threats for the federation as a whole. Though this is a problem felt by the customers, still found to be a concern for the entire supply chain since they are the epicentre of the whole process. It is found that 37 percent of the overall problems with the products lie with this issue. Since the customers today don't have any option they endure with the federation but tomorrow if the problem persists there is every possibility of switch over to competitors' brand leading to loss in market share.

\subsection{Impact of medium risks on supply chain}

\subsubsection{High cost of fodder and medicines}

Cost of fodder and medicine constitute almost 70 percent of the total cost of production. If the fodder and medicine cost increase by just 10 percent of the market price then the cost per litre is increased by Rs.1.50 to make it to Rs.16.27 per litre (earlier Rs.14.77/lt). But concurrently the selling price per litre of milk does not increase and hence the percentage of loss is found to be comparatively larger. It may be noted here that rare cases profit has been detected unless there is a significant level of milk production and severing of labour cost from the total cost expended.

\subsubsection{Lack in leadership skills}

Lack of leadership skills incapacitates secretaries and the field supervisors to disburse their duties smoothly. This makes them inefficient to motivate the milk producers of a certain locality to join societies too. Due to this they can't put forth the demands of the members before the union/federation and hence indirectly arouse the discontentment among the member producers. Continuing with the problem for long run the organizations might come to defunct situation. Since the secretary is the only official at the society level he/she bears the blame once it comes to a defunct position. The field supervisors also take the blame from the union if they won't perform up to the expectations of it. Often it is seen that lack in leaderships do not minimise the gap between the target versus actual milk collections at the society and chilling centre level.

\subsubsection{Delivery risks}

If the milk is not delivered to the production plant on time then the production processes get affected seriously and might increase the risk of perishability on the way and any delay in it will incur more chilling costs. Already it is seen that, the cost of chilling is around 18 percent of the total collection costs, so any delay in the delivery process will lead to incur more costs in chilling.

\subsubsection{Product shortages}

Product shortages are experienced from the production plant especially in the festive seasons. It is highly seemed to be a concern for the semi-durable products (like ghee) which is not manufactured at the plant rather procured from other production units. The desired amount of requirement is drastically lesser than the supply being made in this case. It is observed that the OFR in their case is 70 percent while PFRs of respective products is averaged with more than 75 percent except ghee. In this case, it is somewhere around 45 percent of the demand 
hence reducing the PFR substantially to make it to the minimum level. Though the risk of "product shortages" is not being opined by the production plant respondents still felt to be one of the major concerns. The OFR of 70 percent is still at minimum and a result of lower production and supply creating product shortages. The PFR and OFR are in some cases found to be as low as 30 percent and 20 percent respectively depicting a higher demand and risk aversion attitude of the retailers to extend their order in anticipation of product perishability and loss.

Though demand unpredictability and product shortages seem to be apparently same still is not true. While the former is felt from the downstream members (customers); the latter is widely experienced from the upstream member (production plant).

\subsection{Impact of low risks on supply chain}

\subsubsection{Seasonal fluctuations in production}

Seasonal fluctuation of milk production hampers the profit by increasing the cost of milk production. The milk production during lean seasons decreases by almost 40 percent and hence increases the cost of milk production substantially by 60 percent over the flush seasons. It is detected that the cost increases by 25 percent over the average cost of milk production unlike cost of production in flush seasons. Concurrently it decreases the profit and put the milk producers at stake.

\subsubsection{Process/control/quality risks}

At DCS level the effect of the quality of milk is found to be somewhat disastrous. There is a deduction in amount accrued from the payment if the quality of milk doesn't match with the specified TMS level. Almost two third of the secretaries claim that to get a TMS level of 12.5 percent in the milk production is difficult and depends on proper feeding procedure. In two third of the cases the TMS level is found to be below these specifications and lead to deductions in amount. So the probability of meeting quality related problems is found to be more than 0.60. Ultimately the amount finally received from the union put them in trouble to distribute it among the producer members proportionately. Also there is a high degree of correlation found between the quality of milk and its selling price at their level.

Since the BMCs process the milk collected from the DCSs, there is an every scope of machine failure which obstructs the chilling and foster perishability. Fortunately all of them have two compressors which capacitate chilling an ongoing concern and hence there is no downtime discovered. But due to the lack of collections the average capacity utilization of the plant is found to be around 50 percent. Only 13 percent of the plants found to be operating with more than 75 percent of capacity utilization. Though operating the machineries by unskilled manpower puts the machineries in obsolescence sometimes still this is not reflected in the list of significant risks - may further need more clarifications at their behest. As long as quality is concerned they are also not out of purview of this issue. In almost half of the cases the collections won't meet the desired specifications (TMS of 12.5 percent) which decrease the profit and ROIs. The lower the TMS the lower is the profit, which is found to have an outstanding correlation value of 0.98 . 
In case of the production plant the machine downtime is found to be insignificant (less than 0.01 percent probability) with a capacity utilization of around 60 percent due to lack of procurement. Though there is no downtime found here still there is always a scope for the machinery failure due to improper handling (10 percent probability). But immediately after the damage; the machineries get repaired and hence downtime is virtually ruled out. Mostly (20 percent) it is seen that, the poly-pack machines fail because of overlapping of plastics. There is always a scope for casualties in the plant and hence adequate measures have been taken to curb all these but the eruption of the same can't be ruled out in any given point of time. Since the exact statistics in this connection have not been received, it is avoided to be cited here. The single production plant which caters the dairy product-needs of three districts with a geographical area of more than 11,000 square kms always faces difficulty from controlling issues related to production and distribution. Since quality in production has become mandatory for the plant to meet the customer satisfaction the lower TMS content of milk collected put it under stake.

\subsubsection{Incompatible price w.r.t quality}

Lack of reliability of products together with this risk factor lead to more than 57 percent of the variability in the problems reflected in the customers' buying behaviour. Incompatible price only increases the risk factors by another 33 percent, found to be another major cause of customer dissatisfaction. Ultimately, this adds to the risk pool of other upstream members especially for the production plant, where the basic problem lies with the quality not with the price. Quality and price respectively are concerns for 90 percent and 30 percent of the customers purchasing the brand which depict the importance of the quality in the process. But when it comes to the combination of the duo quality is found to be inferior to the price and hence the mismatch comes up as another threat for the supply chain.

\section{Conclusion}

The dairy-food supply chain is highly a riskier business concern to deal with. No matter what the precautions taken, risks and uncertainties can't be ruled out from the industry. Since it is not possible to avoid them, a proper risk redressal mechanism could at least minimise the impact. The high risk areas are the crucial ones and need to be addressed soon while medium and low risk areas are not to be neglected at the same time. A basic priority for the dairy industry is to ensure that products distributed to the customers are safe and suitable for consumption. Milk borne injuries can be extremely fatal leading to unnecessary litigations and finally tarnish the image of the company in the long run. Since bacteria can grow in milk very rapidly and make it perished, it results in incurring heavy losses and brings down consumers' confidence level. This nature of milk is very unique among all food items; which needs immediate attention. An efficient and effective supply chain management operation could provide for hygienic measures throughout the supply chain by adhering to the proper food value requirements.

\section{References}

Akcaoz, H., Kizilay, H., \& Ozcatalbas, O. (2009). Risk management strategies in dairy 
farming: A case study in Turkey. Journal of Animal and Veterinary Advances, 8(5), 949-958.

Ali, J., \& Kapoor, S. (2008). Farmers' perception on risks in fruits and vegetables production: An empirical study of Uttar Pradesh. Agricultural Economic Research Review, 21(Conference Number), 317-326.

Gorton, M., Dumitrashko, M., \& White, J. (2006). Overcoming supply chain failure in the agri-food sector: A case study from Moldova. Food Policy, 31, 90-103.

Gray, C. F., \& Larson, E. W. (2008). Project management: The managerial process ( $3^{\text {rd }}$ ed.). New Delhi: Tata McGraw-Hill.

Hair, J. F., Anderson, R. E., Tatham, R. L., \& Black, W. C. (1998). Multivariate data analysis. London: Prentice Hall.

IFCN. (2008). IFCN dairy report: For a better understanding of milk production world-wide. Kiel, Germany: Author. Retrieved 7 April, 2009, from www.ifcndairy.org

Juha, M., \& Pentti, J. (2008). Managing risks in organizational purchasing through adaptation of buying centre structure and the buying process. Journal of Purchasing \& Supply Management, 14, 253-262.

Juttner, U. (2005). Supply chain risk management: Understanding the business requirements from a practitioner perspective. International Journal of Logistics Management, 16(1), $120-141$.

Krejcie, R. V., \& Morgan, D. W. (1970). Determining sample size for research activities. Educational and Psychological Measurement, 30, 607-610.

Malhotra, M. K., \& Grover, V. (1998). An assessment of survey research in production and operations management: From constructs to theory. Journal of Operations Management, 16, 407-425.

Mulacahy, R. (2003). Risk management. USA: RMC Publications, Inc.

Nunnally, J. C. (1978). Psychometric theory. Englewood Cliff, NJ: McGraw-Hill Publications.

Ramaswami, B., Ravi, S., \& Chopra, S. D. (2004). State of the Indian farmer: Risk management (Vol. 22). New Delhi: Academic Foundation.

Schoenherr, T., Rao Tummala, V. M., \& Harrison, T. P. (2008). Assessing supply chain risks with the analytic hierarchy process: Providing decision support for the off-shoring decision by a US manufacturing company. Journal of Purchasing \& Supply Management, 14, $100-111$.

Siegel, P. B. (2005). Managing agricultural production risk: Innovations in developing countries. Commodity Risk Management Group, Agricultural and Rural Development Department, World Bank Report No. 32727, Washington D.C.

The Economist Intelligence Unit. (2009). Managing supply chain risk for reward. The 
Economist, 2009, 1-20. Retrieved June 17, 2010, from http://www.acegroup.com

Thun, J. H., \& Hoenig, D. (2009). An empirical analysis of supply chain risk management in the German automotive industry. International Journal of Production Economics, 1-8. Retrieved March 5, 2010, from http://www.ijpe.org

Tiersten, S. (1989). The changing face of purchasing. Electronic Business, 22-27.

United Nations Food and Agricultural Organisation (2008, June). Milk and milk products. Retrieved November 10, 2008, from http://www.unfao.org

Vanany, I., Zailani, S., \& Pujawan, N. (2009). Supply chain risk management: Literature review and future research. International Journal of Information Systems and Supply Chain Management, 2(1), 16-33.

Zsidisin, G. A. (2003). A grounded definition of supply risk. Journal of Purchasing and Supply Management, 9, 217-224.

Zsidisin, G. A., \& Ritchie, R. (2008). Supply chain risk: A handbook of assessment, management, \& performance. New York: Springer International. 